\title{
THE GRADUATE SCHOOL IN MATHEMATICAL PHYSICS AT BIRMINGHAM
} N 1956, a Graduate School in Mathematical
Physics, leading to a diploma, was instituted in
the Department of Mathematical Physics of the
University of Birmingham. It had been noticed
that students who graduated in the honours school of
mathematical physics in the Department seemed well
equipped, and considerably in demand, for work
involving the applications of mathematics to physical
problems in industry, government laboratories, etc.,
because of the training they received in the principles
of physics, and particularly in the techniques of
translating physical problems into mathematical
terms, and of interpreting the solutions from a physical
point of view.

Entry to the honours course at Birmingham is restricted to students of high ability, who must have the appropriate background in their school training, since the three-year course makes fairly heavy demands on the students. It seemed likely therefore that a one-year postgraduate course would be of advantage to students who had taken a degree in mathematics, because they could not-or did not choose to-enter the mathematical physics course, or who graduated from universities at which such a course was not available.

The three years of operation of the Graduate School have provided sufficient experience to judge that it can serve the purpose for which it was intended, and that it imparts to the students knowledge and experience which serves them well in their later work. The course extends over one academic year (October to July) and is normally intended for honours graduates in mathematics with subsidiary physics. In some cases it proved possible to fit in students with somewhat different qualifications. Lecture courses attended by the students include a course in methods of mathematical physics (given so far by Dr. J. G. Valatin, who is in general charge of the Graduate School), which forms the central theme of their introduction to the outlook of a mathematical physicist. In addition, students normally take selected parts of the lecture courses for honours physicists, and those parts of the final-year course for mathematical physicists (electromagnetic theory, hydrodynamics, quantum mechanics) which they have not previously covered, and which suit their particular needs. Other options include mathematical statistics, numerical methods, elasticity theory, statistical mechanics, and usually at least one course in one of the applied science departments. All students attend a weekly seminar arranged specially for the Graduate School in which they contribute themselves, and otherwise hear talks by members of the research group in mathematical physics and others. It has proved possible to arrange for each individual student a combination of courses which suits his particular interests and knowledge.

Although many of these courses are given for other purposes, students find it easy to synthesize their work and to build them into a common foundation of understanding.

The number of students in the course has remained small in the first three years, and is likely to continue small until the existence and purpose of the course become more widely known. It is therefore premature to give any statistics of the subsequent occupations of students who have obtained the diploma. These included work in industry and government laboratories as well as academic research. (One student took up postgraduate work in the Mathematical Physies Department at Birmingham, and two joined an applied science department in the University.)

The development of the Graduate School was greatly aided by the award of advanced course studentships of the Department of Scientific and Industrial Research, and in some cases by grants from the University of Birmingham.

R. E. Peifrlis

\section{WATER-RESOURCES AND WATER-USE SURVEY}

\begin{abstract}
7 HE study of the use and conservation of water resources is a relatively new geophysical science and one that impinges closely on other sciences such as meteorology and climatology, geology and geomorphology, agriculture, economic geography, demography, ete. The importance in the modern world of economic and land-use planning, particularly with reference to so precious a raw material as water, involves the collection of a vast and varied amount of data and information relevant to the assessment of water resources, on not only a national but also an international basis. Two papers*,

* World Meteorological Organization. Technical Note No. 25 Design of Hydrological Networks. Prepared by Max A. Kohler Technical Note No. 26 : Techniques for Surveying Surface-Water Re sources. Prepared by Prof. Ray K. Linsley. Pp. v $+16+\mathrm{xl}+41$. Organization, 1958.) 4 Swiss francs.
\end{abstract}

published by the World Meteorological Organization, are useful statements in this important field, particularly in view of the varying scientific standards of recording and observation that are available and possible in different world regions.

M. A. Kohler summarizes briefly the types of hydrological data, the network density of observations required, and network planning, and the techniques for estimating hydrological data that can be used. Attention is directed to the impracticability of devising a universally standardized procedure and a scheme is put forward for the creation of a minimum cover of permanent full, partial, and temporary observational stations.

The second, longer, technical paper is more closely concerned with techniques for the surveying of surface 